\title{
Electric-Alignment Immobilization of Liquid Crystalline Colloidal Nanosheets with the Aid of a Natural Organic Polymer
}

\section{Supporting Information}

Emiko Mouri ${ }^{1,2}$, Akari Irie $^{1}$, Teruyuki Nakato ${ }^{1,2, *}$

${ }^{1}$ Department of Applied Chemistry, Kyushu Institute of Technology 1-1 Sensui-cho, Tobata, Kitakyushu, Fukuoka 804-8550, Japan.

${ }^{2}$ Strategic Research Unit for Innovative Multiscale Materials, Kyushu Institute of Technology, 1-1 Sensui-cho, Tobata, Kitakyushu, Fukuoka 804-8550, Japan. 


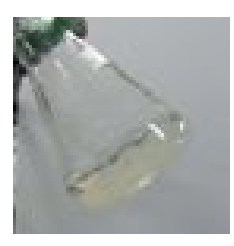

Agar

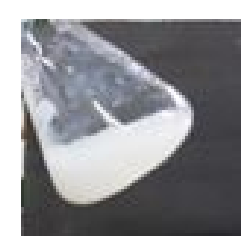

Niobate-Agar

Figure S1 Gel appearances of agar $(0.8 \mathrm{wt} \%)$ and niobate $\left(5 \mathrm{gL}^{-1}\right)-$ agar $(0.8 \mathrm{wt} \%)$ colloidal solutions. 